\title{
Pneumonia risk factors in stroke patients
}

\author{
Paulo Mateus Madureira Soares Mariano' \\ https://orcid.org/0000-0003-0750-9822 \\ Mateus de Sousa Rodrigues ${ }^{2}$ \\ https://orcid.org/0000-0003-4664-2351 \\ Leonardo Fernandes e Santana ${ }^{2}$ \\ https://orcid.org/0000-0001-7729-8392 \\ Manoel Pereira Guimarães ${ }^{2,3}$ \\ https://orcid.org/0000-0001-7780-8946 \\ Paulo Adriano Schwingel ${ }^{3}$ \\ https://orcid.org/0000-0002-2935-3403 \\ Orlando Vieira Gomes ${ }^{2}$ \\ https://orcid.org/0000-0001-6324-7594 \\ José Carlos de Moura ${ }^{2}$ \\ https://orcid.org/0000-0001-6943-1560
}

Complexo Hospitalar Universitário Professor Edgard Santos - HUPES Salvador, Bahia, Brasil.

Universidade Federal do Vale do São Francisco - UNIVASF, Petrolina, Pernambuco, Brasil.

Universidade de Pernambuco UPE, Laboratório de Pesquisas em Desempenho Humano - LAPEDH, Petrolina, Pernambuco, Brasil.

Conflict of interests: Nonexistent

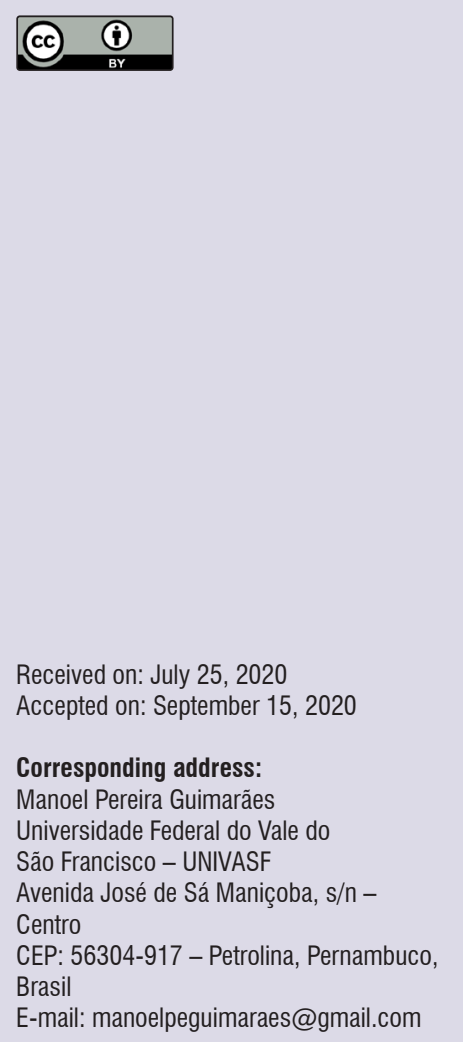

\section{ABSTRACT}

Purpose: to assess the demographic and clinical characteristics associated with the development of pneumonia in post-stroke patients hospitalized in a tertiary hospital, located in the Vale do São Francisco, that covers the states of Pernambuco and Bahia, Brazil.

Methods: a unicentric, observational, analytical, cross-sectional study, based on the medical records of patients diagnosed with stroke and included in the Stroke Registry (RAVESS study). The statistical analysis was made with the chi-square test, Fisher's exact test, and the analysis of variance, with the Bonferroni's post-test, and $\mathrm{P} \leq 0.05$.

Results: data from 69 patients presented with acute stroke were collected, aged $63.2 \pm 16.8$ years; 37 (53.6\%) were females; the prevalence of pneumonia during hospital stay was estimated at 31.9\% (95\% confidence interval: $21.2-44.2 \%)$. In the univariate analysis of predictors for post-stroke pneumonia, the following were identified: older age (72.6 \pm 17.9 vs. $58.8 \pm 14.5 ; P=0.001)$, lower response signal to the Glasgow Coma Scale at admission ( $11.3 \pm 1.8$ vs. $13.3 \pm 2.1 ; P=0.001)$, and higher frequency of dysarthria at admission ( $61.9 \%$ vs. $27.9 \% ; P=0.009)$.

Conclusion: pneumonia was a prevalent complication in post-stroke patients at a Brazilian tertiary hospital. It was related to the patient's older age and the severity of the cerebral event.

Keywords: Stroke; Pneumonia; Risk Factors; Epidemiology 


\section{INTRODUCTION}

Stroke is a neurological syndrome of vascular origin highly prevalent in adults and older adults. It is characterized by the focal or global impairment of the brain functions, beginning suddenly and lasting more than 24 hours, or causing the person's death before this time ${ }^{1,2}$. The medical complications are important causes of morbimortality following a stroke, besides creating possible barriers to the person's recovery. Studies evidenced that the complications not only are common, ranging from 40 to $96 \%$ of the patients, but they also contribute to an unfavorable outcome ${ }^{3,4}$.

In some studies, pneumonia is developed by approximately one third of the patients during the hospital stay after stroke $e^{5}$, with an increase of $10 \%$ in the risk of death in the first 30 days after this cerebral event ${ }^{6}$. Pneumonia, in the first week after the stroke, is also related to an unfavorable outcome in the first three months after the event. Hence, preventive actions, early diagnosis, and intensive care can improve post-stroke outcome?

The lack of standardized criteria for early suspicion for pneumonia in post-stroke patients has significant implications for the clinical practice, such as the appropriate handling of antibiotic therapy, considerations on differential diagnoses, prognostic assessment, and preventive interventions ${ }^{8}$. Despite being a common complication and there being a high post-stroke morbidity rate, developing a score with standardized criteria to early detect it in stroke remains a challenge. Among the most used scores, there are the Age, Atrial Fibrillation, Dysphagia, Sex, Stroke Severity $\left(A^{2} D S^{2}\right)$ and the Acute Ischemic Stroke-Associated Pneumonia Score (AIS-APS) for patients with ischemic stroke, and the Intracerebral Hemorrhage-Associated Pneumonia Score (ICH-APS) for intracerebral hemorrhage, as well as the National Institutes of Health Stroke Scale (ISAN) score for both. However, their use has not yet been validated ${ }^{9,10}$.

Considering that pneumonia is a frequent complication in hospitalized patients with stroke and that it is associated with unfavorable clinical outcomes, studies are made necessary to identify risk factors that can predict the development of pneumonia in high-risk patients. Knowing the predictive factors for pneumonia, either the clinical or the epidemiological ones, can help the health care team to diagnose pneumonia, providing strategies to the early treatment and preventive measures. Therefore, the present study aimed to assess the demographic and clinical characteristics associated with the development of pneumonia in poststroke in-patients in a Brazilian tertiary hospital.

\section{METHODS}

\section{Ethical aspects}

This study complies with the principles of the Declaration of Helsinki. It was approved by the Human Research Ethics Committee of the Universidade Federal do Vale do São Francisco, Brazil, under CAAE number 74847317.8.0000.5196 and approval report number 2.876.953. All the patients or those responsible for them were approached during the hospital stay and informed about the objectives and procedures of the study. After the clarifications, those who agreed to participate in the study signed the informed consent form.

\section{Design and population}

This is a unicentric, observational, analytical, cross-sectional study, based on the medical records of patients diagnosed with ischemic or hemorrhagic stroke and included in the Stroke Registry (RAVESS study, after the Portuguese acronym). All the patients diagnosed with ischemic or hemorrhagic stroke admitted to a University Hospital (which gives priority to the states of Pernambuco and Bahia) between July 2018 and August 2019 were included in the study. The diagnosis of stroke present in the records was based on clinical manifestations and radiological findings with the CT scan of the skull and brain, which had been previously conducted at the said hospital.

The medical records of patients that did not agree to participate in the study or that were diagnosed with cerebral venous thrombosis, transient ischemic attack, and/or cranial neoplasm were excluded from the study. The medical records reporting previous respiratory diseases in the patient, or with incomplete information were excluded as well.

\section{Data collection}

The data collection instrument was developed as a closed-ended questionnaire with categorized options for the following variables: sex, age, smoking, alcoholism, systemic arterial hypertension, diabetes mellitus, previous stroke, type of stroke at admission, dysarthria at admission, Glasgow Coma Scale at admission, pneumonia, length of stay, and clinical outcome (hospital discharge or death). The pneumonia was diagnosed by the assistant physician based on 
clinical and radiological information. The tomographic record identifying the stroke was conducted by the medical team responsible for the clinical follow-up of the patients in the hospital.

\section{Statistical analysis}

The data were processed and analyzed in the SPSS software (SPSS Inc., Chicago, IL, USA, Release 16.0.2, 2008) and Prism software (GraphPad Inc., San Diego, CA, USA, Version 6.01, 2012). Initially, the Shapiro-Wilk test and Bartlett's criteria were used in the descriptive statistical analysis to determine the normality of the data. The homogeneity of the variances and the homoscedasticity were determined with Levene's test. The continuous variables were presented as mean \pm standard deviation (SD), while the categorical variables were expressed in absolute and relative frequencies. Associations between categorical variables were obtained with the help of Pearson's chi-square test and Fisher's exact test. The means between two groups were compared with the t-test for independent samples, whereas the one-way analysis of variance (ANOVA) compared three groups. Bonferroni's post-test was used to identify the differences. All the statistical methods were two-tailed; when calculated, the $p$-values were exact, with a $95 \%$ confidence interval (Cl), and the significance level set at $\leq 0.05$.

\section{RESULTS}

After applying the exclusion criteria, the data of 69 patients were collected $-37(53.6 \%)$ of whom were females (Table 1). The hospitalized patients were in the age range $63.2 \pm 16.8$ years. According to the stroke classification, $45(65.2 \%)$ cases of cerebral ischemia were identified - of whom, 24 (53.3\%) were males. While seven $(50.0 \%)$ of the $14(20.3 \%)$ patients with intraparenchymal cerebral hemorrhage were males, only two $(20.0 \%)$ of the $10(14.5 \%)$ with subarachnoid hemorrhage were men.

Table 1. Clinical and epidemiological data of 69 patients diagnosed with stroke and treated at the emergency room of a tertiary hospital

\begin{tabular}{lc}
\hline Variables & Values $\mathbf{( N = 6 9 )}$ \\
$\mathbf{n}(\%)$
\end{tabular}

SD: standard deviation; SAH: subarachnoid hemorrhage; IPH: intraparenchymal hemorrhage 
The prevalence of pneumonia in this group of patients during hospital stay was estimated at $31.9 \%$ (95\% Cl: $21.2-44.2 \%)$. The stroke patients that had a respiratory tract infection during the stay had a higher mean age $(72.6 \pm 17.9$ vs. $58.8 \pm 14.5 ; P=0.001)$ and a lower response signal in the Glasgow Coma Scale at admission (11.3 \pm 1.8 vs. $13.3 \pm 2.1 ; P=0.001)$. The frequency of dysarthria at admission to the hospital was also statistically higher $(P=0.009)$ in the group of stroke patients that had pneumonia (Table 2). No statistical association was identified between the presence of pneumonia and other variables analyzed in the study.

Table 2. Univariate analysis of pneumonia in hospital stay with clinical and epidemiological data of patients diagnosed with stroke and treated at a tertiary hospital

\begin{tabular}{lccc}
\hline \multirow{2}{*}{ Variables } & \multicolumn{2}{c}{ Pneumonia } & \multirow{2}{*}{ P-value* } \\
\cline { 2 - 3 } & Yes $(\mathbf{n}=\mathbf{2 2})$ & No $(\mathbf{n}=\mathbf{4 7})$ & 0.916 \\
Females & $12(54.5)$ & $25(53.2)$ & 0.001 \\
Age (years), mean \pm SD & $72.6 \pm 17.9$ & $58.8 \pm 14.5$ & 0.664 \\
Smoking & $12(54.5)$ & $23(48.9)$ & 0.416 \\
Alcoholism & $6(27.3)$ & $15(37.5)$ & 0.107 \\
Hypertension & $19(86.4)$ & $32(68.1)$ & 0.979 \\
Diabetes Mellitus & $6(28.6)$ & $13(28.9)$ & 0.470 \\
Previous stroke & $10(55.6)$ & $20(45.5)$ & \\
Type of stroke at admission & & & \\
SAH & $2(9.1)$ & $8(17.0)$ & 0.487 \\
IPH & $6(27.3)$ & $8(17.0)$ & \\
ISchemic & $14(63.6)$ & $31(66.0)$ & 0.009 \\
Dysarthria at admission & $13(61.9)$ & $12(27.9)$ & 0.001 \\
Glasgow at admission (n), mean \pm SD & $11.3 \pm 1.8$ & $13.3 \pm 2.1$ & 0.161 \\
Pneumonia & $23.2 \pm 13.0$ & $17.2 \pm 17.7$ & 0.936 \\
Length of stay (days), mean \pm SD & $2(9.1)$ & $4(8.5)$ & \\
\hline
\end{tabular}

*Pearson chi-square, Fisher's exact test, or one-way ANOVA

SD: standard deviation; SAH: subarachnoid hemorrhage; IPH: intraparenchymal hemorrhage

Considering the type of stroke and analyzing the possible statistical association with clinical and hospital variables (Table 3), it was verified that hospitalized patients with subarachnoid hemorrhage had a longer length of stay $(36.6 \pm 28.2$ days) in relation to the patients with intraparenchymal hemorrhage $(18.3 \pm 9.4$ days) and ischemic stroke (15.5 \pm 12.1 days). Moreover, this subtype of stroke also had a higher frequency $(P=$ 0.001) of patients that died. On the other hand, all the patients with intraparenchymal hemorrhage came to be discharged from the hospital.
No statistically significant differences were identified in the analysis of the relationship of clinical and hospital variables with the type of stroke of patients who developed a respiratory tract infection - except for the final therapeutic outcome (Table 4). It was verified that all the patients with subarachnoid hemorrhage that developed pneumonia during their hospital stay died, whereas all the hospitalized patients with intraparenchymal hemorrhage or ischemic stroke that had a respiratory tract infection survived and were discharged from the hospital. 
Table 3. Univariate analysis of the type of stroke at admission with clinical and epidemiological data of patients diagnosed with stroke and treated at a tertiary hospital

\begin{tabular}{lcccc}
\hline \multirow{2}{*}{ Variables } & \multicolumn{3}{c}{ Type of stroke } & \multirow{2}{*}{ P-value * } \\
\cline { 2 - 4 } & $\begin{array}{c}\text { SAH } \\
(\mathbf{n}=\mathbf{1 0})\end{array}$ & $\begin{array}{c}\mathbf{I P H} \\
(\mathbf{n}=\mathbf{1 4})\end{array}$ & $\begin{array}{c}\text { Ischemic } \\
(\mathbf{n}=\mathbf{4 5})\end{array}$ & \\
\hline Age (years), mean \pm SD & $57.1 \pm 12.3$ & $67.6 \pm 16.9$ & $63.2 \pm 17.6$ & 0.328 \\
Hypertension & $7(70.0)$ & $11(78.6)$ & $33(73.3)$ & 0.885 \\
Diabetes Mellitus & $1(12.5)$ & $2(14.3)$ & $16(36.4)$ & 0.157 \\
Previous stroke & $2(25.0)$ & $6(46.2)$ & $22(53.7)$ & 0.327 \\
Dysarthria at admission & $3(42.9)$ & $9(35.7)$ & $17(39.5)$ & 0.945 \\
Glasgow at admission (n), mean \pm SD & $12.3 \pm 2.4$ & $11.8 \pm 2.1$ & $13.1 \pm 2.1$ & 0.126 \\
Pneumonia & $2(20.0)$ & $6(42.9)$ & $14(31.1)$ & 0.487 \\
Length of stay (days), mean $\pm S D$ & $36.6 \pm 28.2^{\mathrm{a}}$ & $18.3 \pm 9.4^{\mathrm{b}}$ & $15.5 \pm 12.1^{\mathrm{b}}$ & 0.001 \\
In-hospital death & $4(40.0)^{\mathrm{a}}$ & $0(0.0)^{\mathrm{b}}$ & $2(4.4)^{\mathrm{b}}$ & 0.001 \\
\hline
\end{tabular}

*Pearson chi-square, or one-way ANOVA. Different letters represent a statistical difference in Bonferroni's post-test, or to the chi-square test SD: standard deviation; SAH: subarachnoid hemorrhage; IPH: intraparenchymal hemorrhage

Table 4. Bivariate analysis of patients with a stroke and pneumonia treated at a tertiary hospital

\begin{tabular}{|c|c|c|c|c|}
\hline \multirow[b]{2}{*}{ Variables } & \multicolumn{3}{|c|}{$\begin{array}{l}\text { Type of stroke in the patients } \\
\text { diagnosed with pneumonia }\end{array}$} & \multirow{2}{*}{ P-value * } \\
\hline & $\begin{array}{c}\text { SAH } \\
(n=2)\end{array}$ & $\begin{array}{c}\text { IPH } \\
(n=6)\end{array}$ & $\begin{array}{c}\text { Ischemic } \\
(n=14)\end{array}$ & \\
\hline Age (years), mean $\pm S D$ & $68.5 \pm 13.4$ & $76.2 \pm 20.4$ & $71.7 \pm 18.3$ & 0.842 \\
\hline Diabetes Mellitus & $1(50.0)$ & $0(0.0)$ & $5(35.7)$ & 0.176 \\
\hline Previous stroke & $1(50.0)$ & $3(50.0)$ & $6(42.9)$ & 0.644 \\
\hline Dysarthria at admission & $0(-)$ & $3(50.0)$ & $10(66.7)$ & 0.283 \\
\hline Glasgow at admission (n), mean \pm SD & $7.5 \pm 10.6$ & $10.4 \pm 0.9$ & $11.4 \pm 1.7$ & 0.781 \\
\hline Length of stay (days), mean $\pm S D$ & $32.0 \pm 21.2$ & $20.7 \pm 7.4$ & $23.0 \pm 14.2$ & 0.584 \\
\hline In-hospital death & $2(100.0)^{a}$ & $0(0.0)^{\mathrm{b}}$ & $0(0.0)^{b}$ & 0.001 \\
\hline
\end{tabular}

*Pearson chi-square, or one-way ANOVA. Different letters represent a statistical difference to the chi-square test

SD: standard deviation; SAH: subarachnoid hemorrhage; IPH: intraparenchymal hemorrhage

\section{DISCUSSION}

Post-stroke pneumonia occurred in 22 of the 69 patients researched, which is compatible with the studies with higher prevalence ${ }^{5,7,11-14}$. The high prevalence of pneumonia in the service may be related to a lack of structure and specialized multidisciplinary team to work at the hospital entry point. A previous study ${ }^{11}$ demonstrated that personalized and multidisciplinary care resulted in lower complication rates, improved quality of life, and reduced mortality in the long run, without prolonging the length of stay. In the present study, pneumonia was associated with risk factors such as age, presence of dysarthria at admission, and more severe impairment, classified with the Glasgow Coma Score. These findings are compatible with other studies ${ }^{15-17}$ and evidence a greater risk of developing pneumonia in older patients, with greater oral dysfunction and more impaired levels of awareness.

In general, the patients with a lower Glasgow Coma Score are those with a broader area affected by the infarction or hemorrhage, with greater sensory loss. Thus, they are the most susceptible to developing bronchoaspiration and pneumonia ${ }^{18}$. However, most of the studies ${ }^{18-21}$ use the presence of dysphagia instead of dysarthria as a predictive factor for pneumonia. In this study, though, there were limitations, as well as the absence of a trained professional in the health care team at the hospital admission to evaluate dysphagia. Hence, dysarthria was chosen to be used as a predictive factor for pneumonia ${ }^{12}$. Moreover, the presence of dysarthria also appears in the literature 
as a predictive factor for dysphagia, which contributes to the greater reliability of the results obtained in the present study ${ }^{12}$.

No association was observed between biological sex and the prevalence of pneumonia. Nevertheless, the literature seems to show a relationship with males. In this study, a greater prevalence of stroke in females was noted, although the majority of previous studies associated the males with a greater risk of stroke $e^{7,13,14}$. Such findings may have a relationship with the profile of the population studied, as well as limitations during the data collection and acceptance to participate in the study.

No significant relationship was identified between the development of pneumonia and the type of stroke. Nonetheless, a higher frequency of pneumonia is related to hemorrhagic stroke ${ }^{13}$. This predisposition may also be explained by the prolonged length of stay, or a lower NIHSS score. Such a relationship may not have been identified in this study because of the small number of patients with hemorrhagic stroke. Moreover, no significant relationship was observed between smoking, alcoholism, arterial hypertension, diabetes mellitus, or previous stroke with the development of pneumonia. In the studies evaluated, no correlation was identified between these factors and the development of pneumonia, either ${ }^{3,6,11}$.

No statistical difference was identified between the length of hospital stay or the final outcome and the presence of pneumonia. However, previous studies 3,6 relate the presence of pneumonia to more prolonged hospital stays or more unfavorable outcomes. On the other hand, hospitalized patients with subarachnoid hemorrhage had a prolonged length of stay associated with an unfavorable clinical outcome in the study. These findings are probably related to the greater severity of subarachnoid hemorrhage in these patients, often needing a neurosurgical intervention and orotracheal intubation, with greater complications in the short and long run.

This study explored a range of variables related to the development of pneumonia in stroke patients, including both demographic and clinical data. Moreover, the results of the present study were compared with those presented in previous research ${ }^{5,7,13,14}$, which confirm the multifactorial component of the development of pneumonia in these patients.

Differences between the findings predictive of pneumonia in this study and the literature ${ }^{5,7,13,14}$ can be explained in part by the diverging inclusion criteria and the variety in the identification and registry of complications - which explains the great variety of prevalence of pneumonia and its predictive findings. It is a consensus, and it has been demonstrated in previous studies, that a multiprofessional intervention with early mobilization and the assessment of swallowing and pulmonary function in stroke patients reduce the risk of complications, reduce mortality, and improve the prognosis ${ }^{22}$.

Furthermore, it is concluded that applying a risk score for pneumonia would help infection surveillance. However, there is no evidence for prophylactic antibiotic therapy, nor internationally validated scores. The development of pneumonia in stroke patients has multifactorial causes; hence, the clinical assessment and follow-up by a specialized multidisciplinary team are essential to identify risk factors and prevent complications.

This study has limitations, highlighting that, since it is based on information collected by multiple professionals and on data from electronic medical records, it is subject to deficient information records and disorganized reports. Not all the variables reported in previous studies were assessed as possible risk factors for pneumonia, such as a history of dementia, localization of the stroke, oral hygiene, NIHSS, atrial fibrillation, and dysphagia. Hence, including other risk factors in the analysis and expanding the sample size are essential to assess the frequency of pneumonia in the population studied, besides the reliable and complete record of the findings in the medical records.

Despite the limitations, the study has a clinical and epidemiologic impact since some variables had statistical and clinical significance, even with a small sample of patients. Some findings in this study corroborate what has been demonstrated in other studies and confirm the need for the multidisciplinary assessment and intervention to contribute to more favorable clinical outcomes.

\section{CONCLUSION}

Based on the analyses made, it can be concluded that the development of pneumonia in hospitalized stroke patients, in a Brazilian tertiary hospital, proved to be related to the severity of the cerebral event, the patient's age, the lower classification in the Glasgow Score, and older age than that of the population that did not develop pneumonia. Gender, alcoholism, and smoking had no association with respiratory condition resulting from dysarthria. The findings of this study conform, in part, with the international literature, regarding the issue addressed. 


\section{REFERENCES}

1. Organização Mundial da Saúde. Manual STEPS de acidentes vascular cerebrais da OMS: enfoque passo a passo para vigilância de acidentes vascular cerebrais. Genebra: OMS; 2006.

2. Rodrigues MS, Santana LF, Galvão IM. Modifiable and non-modifiable risk factors for ischemic stroke: a descriptive approach. Rev Med. 2017;96(3):187-92.

3. Kumar S, Selim MH, Caplan LR. Medical complications after stroke. Lancet Neurol. 2010;9(1):105-18. DOI:10.1016/ S1474-4422(09)70266-2

4. Davenport RJ, Dennis MS, Wellwood I, Warlow C. Complications after acute stroke. Stroke. 1996:27(3):415-20. DOI:10.1161/01.str.27.3.415

5. Sellars C, Bowie L, Bagg J, Sweeney MP, Miller $\mathrm{H}$, Tilston $\mathrm{J}$ et al. Risk factors for chest infection in acute stroke: a prospective cohort study. Stroke. 2007:38(8):2284-91. DOI: 10.1161/ STROKEAHA.106.478156

6. Katzan IL, Cebul RD, Husak SH, Dawson NV, Baker DW. The effect of pneumonia on mortality among patients hospitalized for acute stroke. Neurology. 2003:60(4):620-5. DOI: 10.1212/01. wnl.0000046586.38284.60

7. GAIN International Steering Committee and Investigators, Aslanyan S, Weir CJ, Diener HC, Kaste M, Lees KR. Pneumonia and urinary tract infection after acute ischaemic stroke: a tertiary analysis of the GAIN International trial. Eur J Neurol. 2004;11(1):49-53. DOI: 10.1046/j.1468-1331.2003.00749.x

8. Kishore AK, Vail A, Chamorro A, Garau J, Hopkins SJ, Di Napoli M et al. How is pneumonia diagnosed in clinical stroke research? A systematic review and meta-analysis. Stroke. 2005;46(5):1202-9. DOI: 10.1161/STROKEAHA.114.007843

9. Westendorp WF, Vermeij J-D, Hilkens NA, Brouwer MC, Algra A, van der Worp HB et al. Development and internal validation of a prediction rule for post-stroke infection and post-stroke pneumonia in acute stroke patients. Eur Stroke J. 2018;3(2):136-44. DOI:10.1177/2396987318764519

10. Kishore AK, Vail A, Bray BD, Chamorro A, Napoli MD, Kalra $L$ et al. Clinical risk scores for predicting stroke-associated pneumonia: a systematic review. Eur Stroke J. 2016;1(2):76-84. DOI:10.1177/2396987316651759
11. Stroke Unit Trialists' Collaboration. Organised inpatient (stroke unit) care for stroke. Cochrane Database of Syst Rev. 2007;(4):CD000197. DOI:10.1002/14651858.CD000197.pub3

12. Mann G, Hankey GJ, Cameron D. Swallowing disorders following acute stroke: prevalence and diagnostic accuracy. Cerebrovasc Dis. 2000;10(5):380-6. DOI:10.1159/000016094

13. Almeida SR, Bahia MM, Lima FO, Paschoal IA, Cardoso TA, Li LM. Predictors of pneumonia in acute stroke in patients in an emergency unit. Arq Neuropsiquiatr. 2015;73(5):415-9. DOI:10.1590/0004-282X20150046

14. Kwon HM, Jeong SW, Lee SH, Yoon BW. The pneumonia score: a simple grading scale for prediction of pneumonia after acute stroke. Am J Infect Control. 2006;34(2):64-8. DOI:10.1016/j. ajic.2005.06.011

15. Toufen JC, Camargo FP, Carvalho CRR. Pneumonia aspirativa associada a alterações da deglutição: relato de caso. Rev Bras Ter Intensiva. 2007;19(1):118-122. DOI:10.1590/ S0103-507X2007000100016

16. Ribeiro BT. Pneumonia aspirativa no idoso [dissertação]. Manhuaçu (MG): Faculdade de Igarassu; 2018.

17. Miranda RPC. Pneumonia no acidente vascular cerebral: frequência, preditores e desfechos associados [dissertação]. Ribeirão Preto (SP): Universidade de São Paulo; 2018.

18. Kishore AK, Vail A, Jeans AR, Chamorro A, Napoli $M$, Kalra $L$ et al. Microbiological etiologies of pneumonia complicating stroke: a systematic review. Stroke. 2018;49(7):1602-9. DOI:10.1161/ STROKEAHA.117.020250

19. Pacheco-Castilho AC, Vanin GM, Dantas RO, Pontes-Neto OM, Martino R. Dysphagia and associated pneumonia in stroke patients from Brazil: a systematic review. Dysphagia. 2019;34(4):499-520 DOI:10.1007/s00455-019-10021-0

20. Yeh SJ, Huang KY, Wang TG, Chen YC, Chen $\mathrm{CH}$, Tang SC et al. Dysphagia screening decreases pneumonia in acute stroke patients admitted to the stroke intensive care unit. J Neurol Sci. 2011;306(12):38-41. DOI:10.1016/j.jns.2011.04.001

21. Crary MA, Mann GD, Groher ME. Initial psychometric assessment of a functional oral intake scale for dysphagia in stroke patients. Arch Phys Med Rehab. 2005;86(8):1516-20. DOI: 10.1016/j. apmr.2004.11.049 
22. Adams HP Jr, del Zoppo G, Alberts MJ, Bhatt DL, Brass L, Furlan A et al. Guidelines for the early management of adults with ischemic stroke: a guideline from the American Heart Association/ American Stroke Association Stroke Council, Clinical Cardiology Council, Cardiovascular Radiology and Intervention Council, and the Atherosclerotic Peripheral Vascular Disease and Quality of Care Outcomes in Research Interdisciplinary Working Groups: the American Academy of Neurology affirms the value of this guideline as an educational tool for neurologists. Stroke. 2007;38(5):1655-711. DOI:10.1161/STROKEAHA.107.181486 